\title{
ACM's Open-Conference Principle and Political Reality
}

ACM's Open-Conference Statement starts with a lofty principle: "The open exchange of ideas and the freedom of thought and expression are central to the aims and goals of ACM

and its conferences. These aims and goals require an environment that recognizes the inherent worth of every person and group, that fosters dignity, understanding, and mutual respect, and that embraces diversity." (See https://www. acm.org/conferences.) This principle reflects ACM's mission of "advance computing as a science and a profession; enable professional development; and promote policies and research that benefit society." In the past few weeks, however, this principle has been gravely tested.

In March 2016, the U.S. State of North Carolina passed a sweeping law (House Bill 2-HB2) that reversed a local ordinance that had extended some rights to people who are gay or transgender. The new law also nullified local ordinances around the state that would have expanded protections for the LGBT community. Several U.S. localities issued travel bans in response to HB2, limiting travel to North Carolina. In January 2017, the ACM SIGMOD Executive Committee decided to move the SIGMOD/ PODS 2017 conference out of North Carolina to a new location (see statement here: http://wp.sigmod.org/?p=2079). This decision resolved the issue for one conference. Unfortunately, in the 2017 legislative session, state legislators in 11 other U.S. states have pre-filed or introduced legislation that would restrict access to multiuser restrooms, locker rooms, and other sex-segregated facilities on the basis of a certain definition of sex or gender ("bathroom bills"). The SIGMOD/PODS 2018 conference is cur- rently slated for Houston, Texas, but this plan is now in jeopardy as Texas is one of the states that is discussing passing a "bathroom bill."

But the bathroom-bill issue was dwarfed by an Executive Order issued by U.S. President Trump on Jan. 27, 2017, which banned nationals of seven Muslim-majority countries from entering the U.S. for at least the next 90 days. This includes persons with valid U.S. visas, as well as-at least initially-U.S. permanent residents. This Executive Order covers not only new arrivals to the U.S., but also persons who have been residing in the U.S. and are temporarily outside the U.S. In response to this executive order, ACM expressed grave concerns and urged the lifting of the visa suspension so as not to curtail the studies or contributions of scientists and researchers. I'd like to see ACM go farther and band with other professional societies to fight the Executive Order; perhaps this will have happened by the time this letter is published.

As this issue goes to print, we do not know how the status of the Executive Order will unfold. There are strong arguments against the constitutionality of the Order, and lawsuits against the U.S. government have already been filed. But it may take months if not years, for the legal process to conclude, and the outcome is far from certain. In the meantime, if we follow the SIGMOD precedent, ACM should avoid holding conferences in the U.S. Should it? I think not.
In fact, while I appreciate the reasoning that led the SIGMOD Executive Committee to decide to relocate the 2017 conference away from North Carolina, I disagree with the decision. ACM is a global professional society. Its OpenConference Principle has to be interpreted from that perspective. Undoubtedly, there are going to be more liberal and less liberal interpretations. Should all ACM conferences be held in California, which tends to be the most liberal state in the U.S.? Or, in view of the Executive Order, how about moving all ACM conferences to Sweden? This is not only impractical, but, in my opinion, not even right. In fact, the ACM SIGMOD/PODS 2007 conference was held in Beijing, China. There are those who would have argued then that China's human-rights record is not up to Western standards, so ACM should not hold conferences in China. But the ACM SIGMOD Executive Committee decided then, correctly, I believe, that going to China rather than avoiding China would better serve the case of open conferences.

The Open-Conference Principle is aimed at benefiting society. When we boycott a particular locality, we are also telling our colleagues in that locality, who are likely to be supporting the cause of open and just society, that we would rather stay away than come and support their fight. This is unlikely, I believe, to benefit society. Boycotting may feel right, but I doubt that it would be productive. Staying and fighting for a cause-though it is far from clear what the best way of doing it is - may be much harder, but is the right path.

Follow me on Facebook, Google+, and Twitter.

Moshe Y. Vardi, EDITOR-IN-CHIEF

Copyright held by author. 